\title{
Dilatometric Identification of Bainitic Transformation during Q-P Processing of 42SiCr Medium Carbon Steel
}

\author{
Štěpán Jeníček, Jiř́ Vrtáček, Ivan Vorel, Tomáš Janda \\ University of West Bohemia, Regional Technological Institute, Univerzitní 22, Plzeň, Czech Republic, E-mail: \\ jeniceks@rti.zcu.cz,vrtacekj@rti.zcu.cz, janda@rti.zcu.cz
}

Q-P process is one of the latest techniques for heat treatment of high-strength steels with increased silicon levels. It is believed to be based on diffusion and migration of carbon between martensite and untransformed austenite, where the latter becomes enriched with carbon, and therefore becomes thermodynamically stable. However, the question remains whether much of the carbon partitioning in the Q-P process might be the result of the competing bainitic transformation induced by arrested quenching below the $\mathbf{M}_{\mathrm{s}}$ temperature. This paper explores the use of dilatometry for identifying the products of austenite decomposition during Q-P processing of medium-carbon $42 \mathrm{SiCr}$ low-alloy steel.

Keywords: Q-P processing, martensite, bainite, dilatometry

\section{Introduction}

The key steps in Q-P processing (quenching and partitioning) of steel are interrupted quenching below the Ms (the quenching stage) and subsequent reheating to the partitioning temperature. The typical partitioning temperature is above the $\mathrm{M}_{\mathrm{s}}$ of the steel [1, 2]. Untransformed austenite becomes stabilised by absorbing carbon which migrates from martensite at the partitioning stage [3]. However, the underlying processes are not quite clear. Where austenite is homogeneous prior to Q-P processing and since martensitic transformation is diffusionless, the martensite which forms during quenching will have the same chemical composition as untransformed austenite. The question then arises what the driving force for carbon diffusion during the partitioning stage is - because no carbon concentration gradient between martensite and untransformed austenite can be expected to exist. Besides, one cannot expect carbon partitioning to be induced by martensite tempering which involves short-range migration and typically occurs at very low temperatures. Yet, experiments revealed that untransformed austenite does become enriched with carbon during the partitioning stage [4]. One plausible and very likely explanation for this paradox is that enrichment of untransformed austenite occurs with carbon whose source is not fresh martensite formed during quenching but bainitic ferrite which emerged in the partitioning stage because bainitic transformation was accelerated by previous martensitic transformation [5]. This dilatometer-based investigation explored the phase transformations which are induced in
42SiCr steel by Q-P processing and aimed to clarify whether untransformed austenite may transform to bainite during Q-P process.

\section{Materials and methods}

The experimental material was medium-carbon low-alloy steel with $0.43 \% \mathrm{C}, 0.55 \% \mathrm{Mn}, 2 \% \mathrm{Si}$ and $1.45 \% \mathrm{Cr}$. It was supplied in the form of $60-\mathrm{kg}$ ingots. They were sectioned and homogenized for 6 hours at $1200^{\circ} \mathrm{C}$ in an argon atmosphere and normalized at $950^{\circ} \mathrm{C}$ for 2 hours. The annealed parts of the ingots were hot-forged into bars $18 \mathrm{~mm}$ in diameter. The forged bars were then homogenized at $1200^{\circ} \mathrm{C}$ for 3 hours in a protective atmosphere and normalized at $950^{\circ} \mathrm{C}$ for 2 hours. Specimens were machined from the bars and processed in L78 RITA quenching dilatometer.

Time-temperature-transformation (TT'T) and time-temperature-austenitization (TTA) diagrams for the steel were determined by calculation using JMatPro. Based on this data, an approximate temperature and time for full austenitization and homogenization of austenite were determined (Fig. 1). Using a dilatometer, the value of $\mathrm{M}_{\mathrm{s}}=280^{\circ} \mathrm{C}$ was found for the cooling rate of $50^{\circ} \mathrm{C} / \mathrm{s}$.

Dilatometer measurement was then performed on the test specimens. The sequences were simulations of defined Q-P process routes (Fig.2). Their design was to enable monitoring of the effect of quenching and partitioning temperatures - above and below the $\mathrm{M}_{\mathrm{s}}-$ on specimen expansion and contraction in response to the phase transformation taking place. 


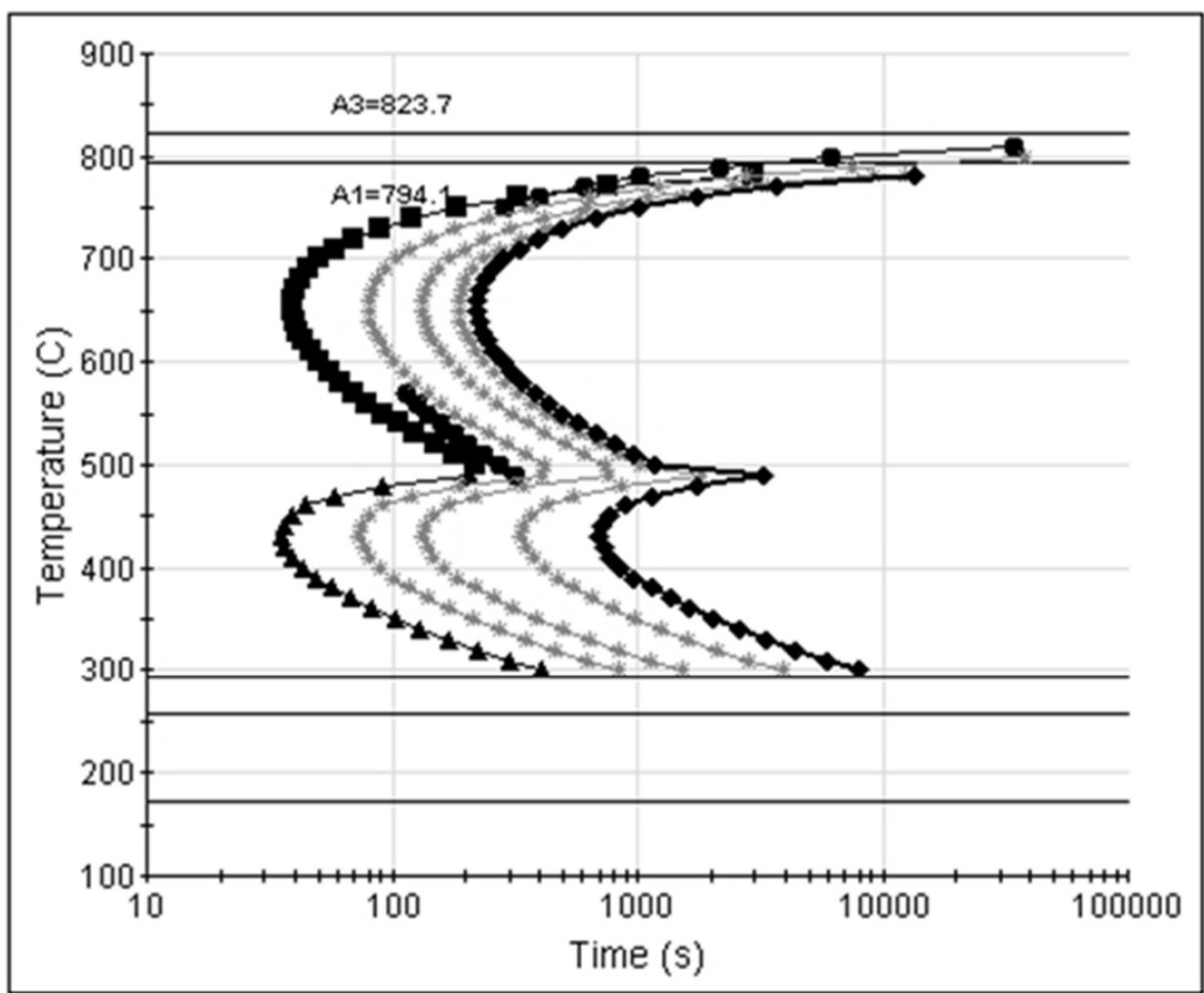

Perrite(1\%)

Pearlite(1\%)

\#Bainite(1\%)

* Transformed(10\%)

* Transformed(50\%)

* Transformed(90\%)

Completion

Fig. 1 TTT diagram of the 42SiCr steel

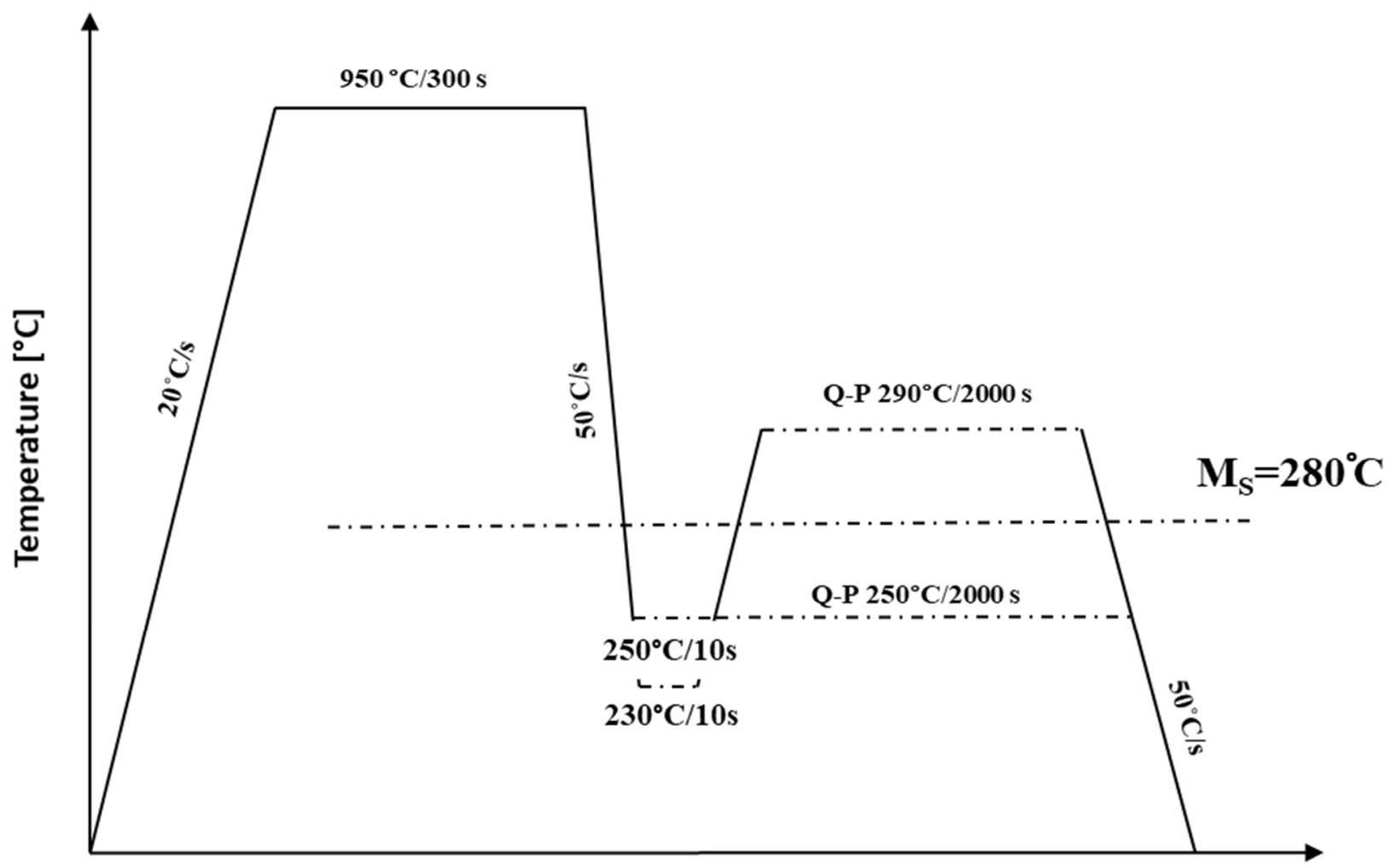

Time [s]

Fig. 2 Diagram of Q-P processing routes

\section{Results and discussion}

The dilatometer measurement led to several conclusions. In all the routes, the specimens showed linear expansion in the partitioning stage. (Fig.3) [6,7]. It occurred immediately after the specimen had reached the partitioning temperature. 


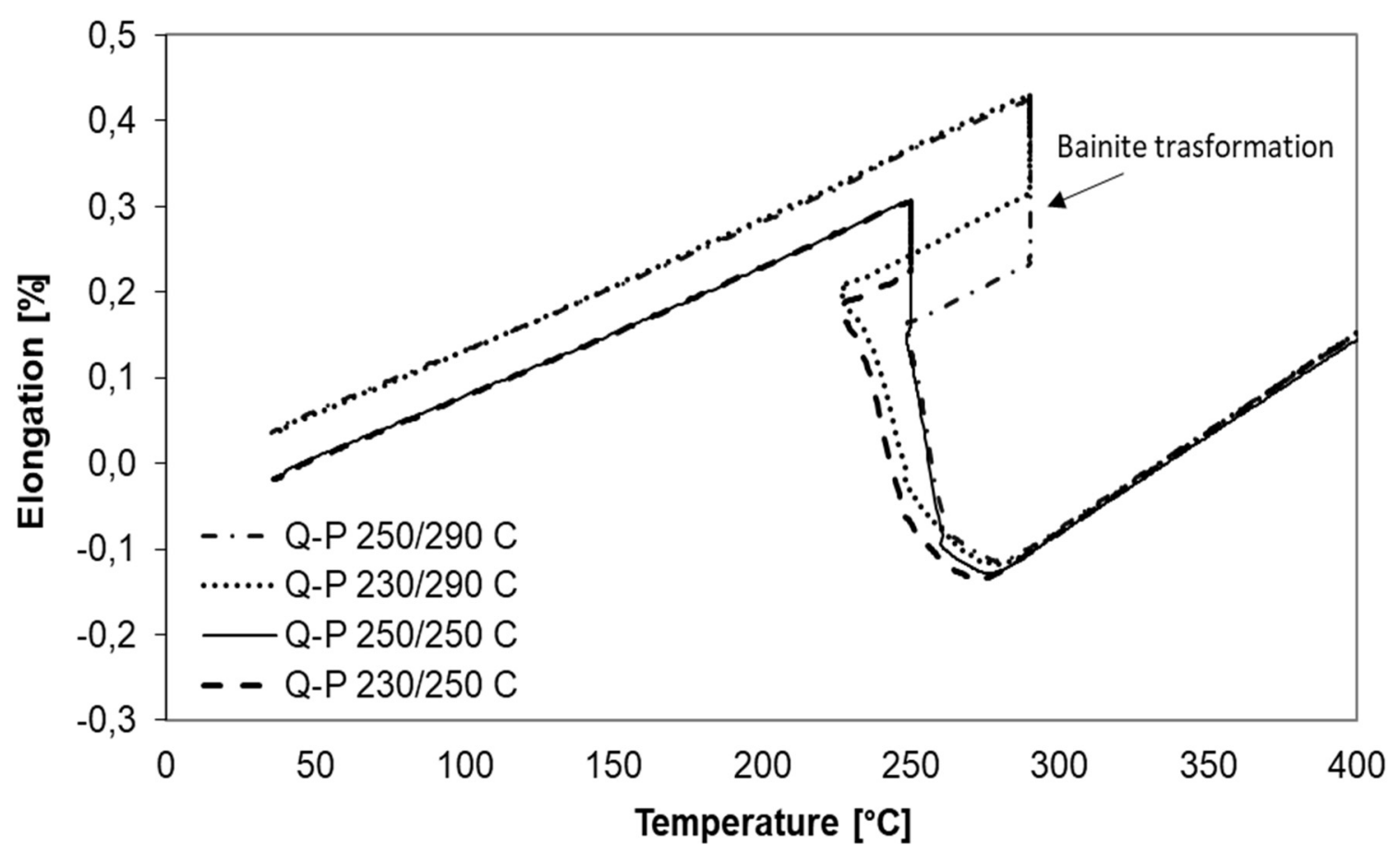

Fig. 3 Dilatometer curves for various Q-P process conditions

As transformation of austenite to martensite is athermal, it is certain that this linear expansion was not related to martensitic transformation. Also, the expansion appears not to have been related to carbon diffusion, specifically to tempering of martensite produced by quenching. This is based on numerous conclusions presented in professional resources where contraction was reported for all dilatometer measurements on test specimens [8,9]. In this case, the segments of dilatometer curves related to the partitioning temperature showed expansion for all specimens (Fig. 4 through 11) [10].

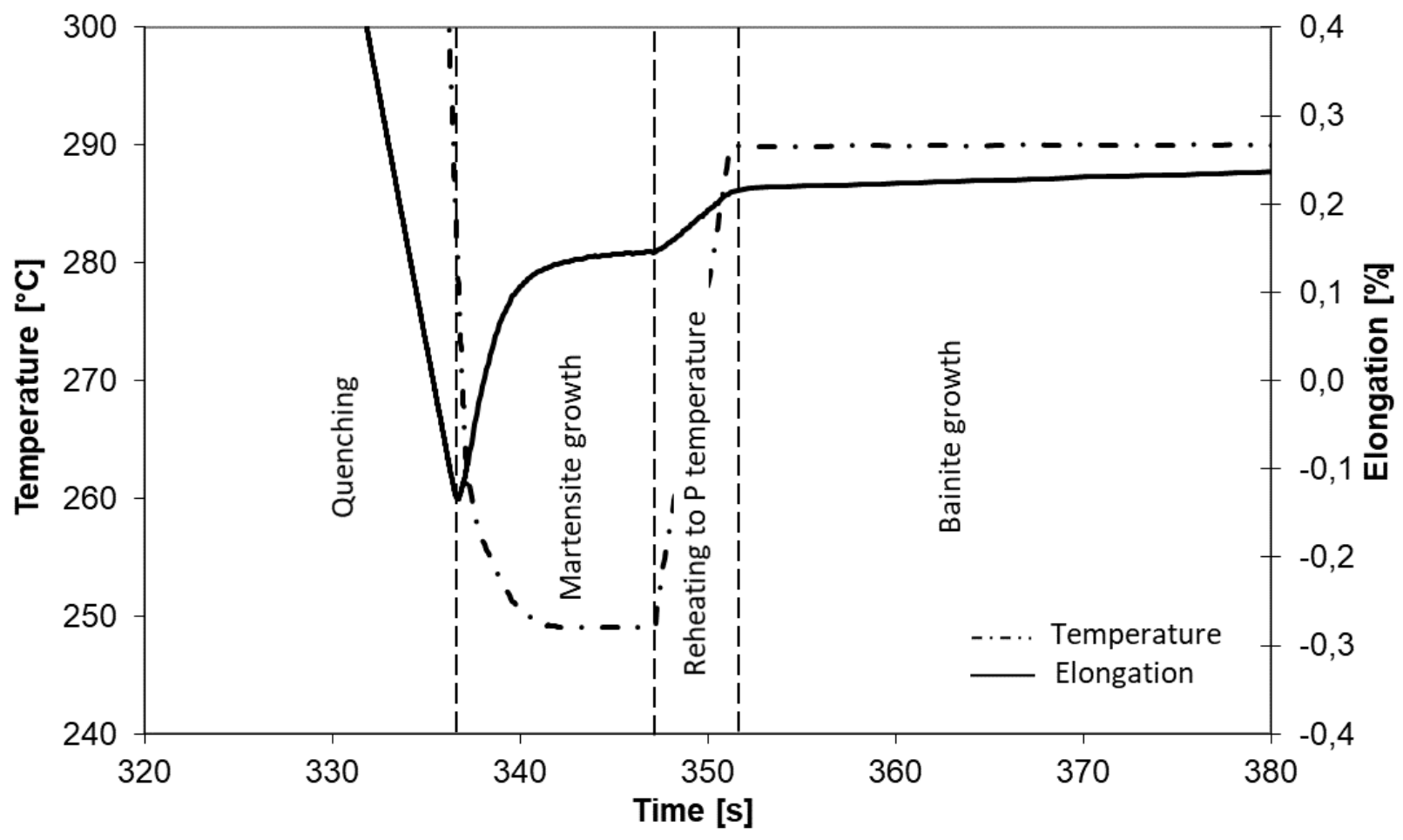

Fig. 4 Detail of dilatometer curve - process route Q-P $250 / 290^{\circ} \mathrm{C}$ 
Considering the above arguments, the changes in length can be attributed to microstructural processes associated with the formation of bainitic ferrite and carbon diffusion [11-14]. Hence, carbon partitioning between ferritic and austenitic phases does occur during Q-P processing but that ferritic phase is in fact bainite, not martensite. This can also explain how migration (diffusion) of carbon occurs between the ferritic and austenitic phases (due to negligible solubility of carbon in bainitic ferrite) instead of migration from martensite in which carbon concentration is roughly the same as in untransformed austenite.

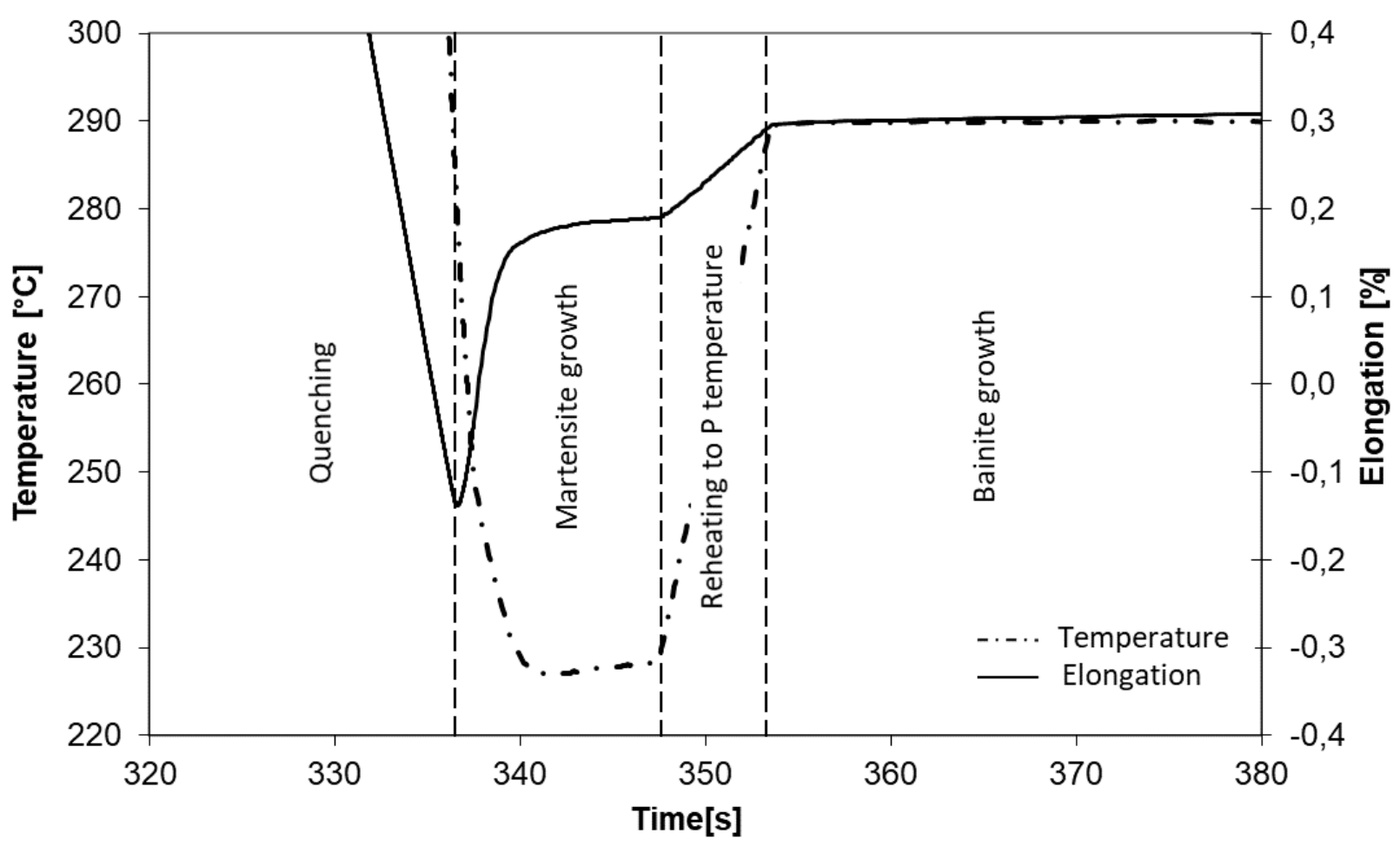

Fig. 5 Detail of a dilatometer curve - process route Q-P $230 / 290^{\circ} \mathrm{C}$

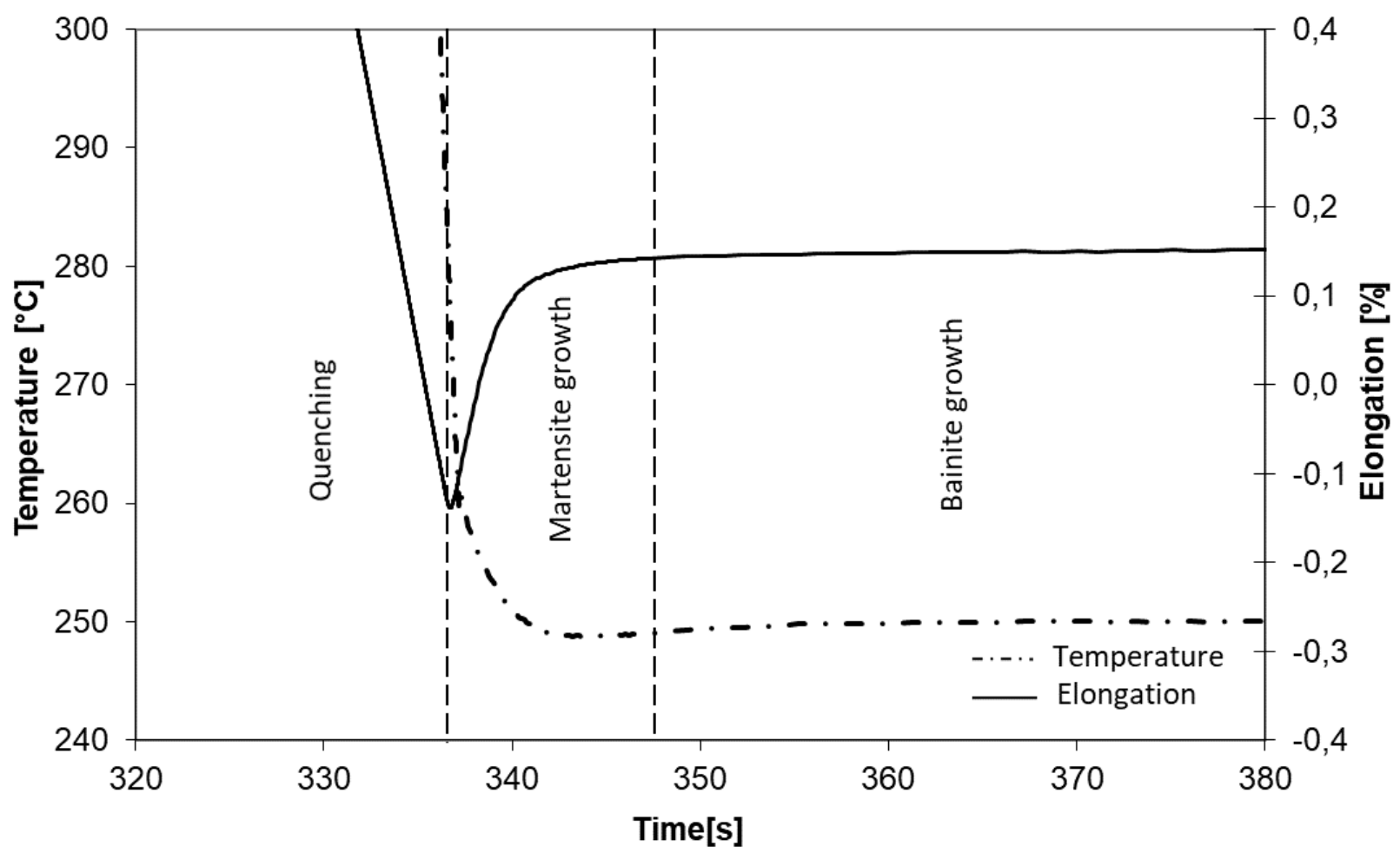

Fig. 6 Detail of a dilatometer curve - process route Q-P $250 / 250^{\circ} \mathrm{C}$ 
One important finding about the behaviour of phase transformations was that bainitic transformation took place at temperatures which were higher than the $\mathrm{M}_{\mathrm{s}}\left(280^{\circ} \mathrm{C}\right)$ - process routes Q-P $250 / 290^{\circ} \mathrm{C}$, Q-P $230 / 290^{\circ} \mathrm{C}$ - as well as lower than the $\mathrm{M}_{\mathrm{s}}$ - process routes Q-P $250 / 250^{\circ} \mathrm{C}$, Q-P $230 / 250^{\circ} \mathrm{C}$. It appears certain that bainite formation is also possible in the temperature interval in which austenite decomposition to martensite is normally the only transformation to occur. The cause of this must have been a change in the thermodynamic driving force, leading to decomposition of austenite to bainitic ferrite. One can assume that untransformed austenite must have undergone changes which eventually depressed the $M_{s}$ temperature and shifted the transformation curves towards shorter times.

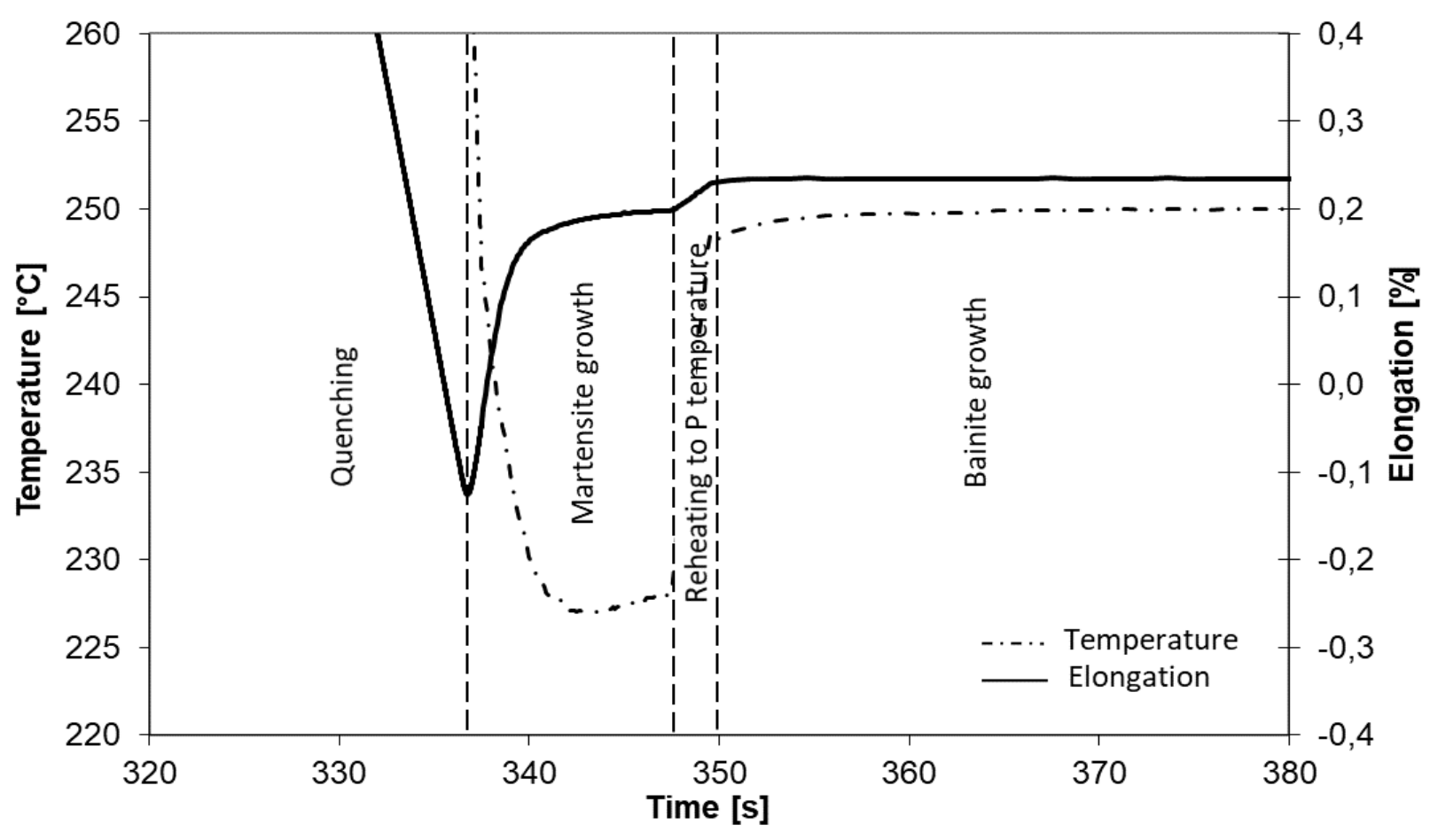

Fig. 7 Detail of a dilatometer curve - process route Q-P $230 / 250^{\circ} \mathrm{C}$

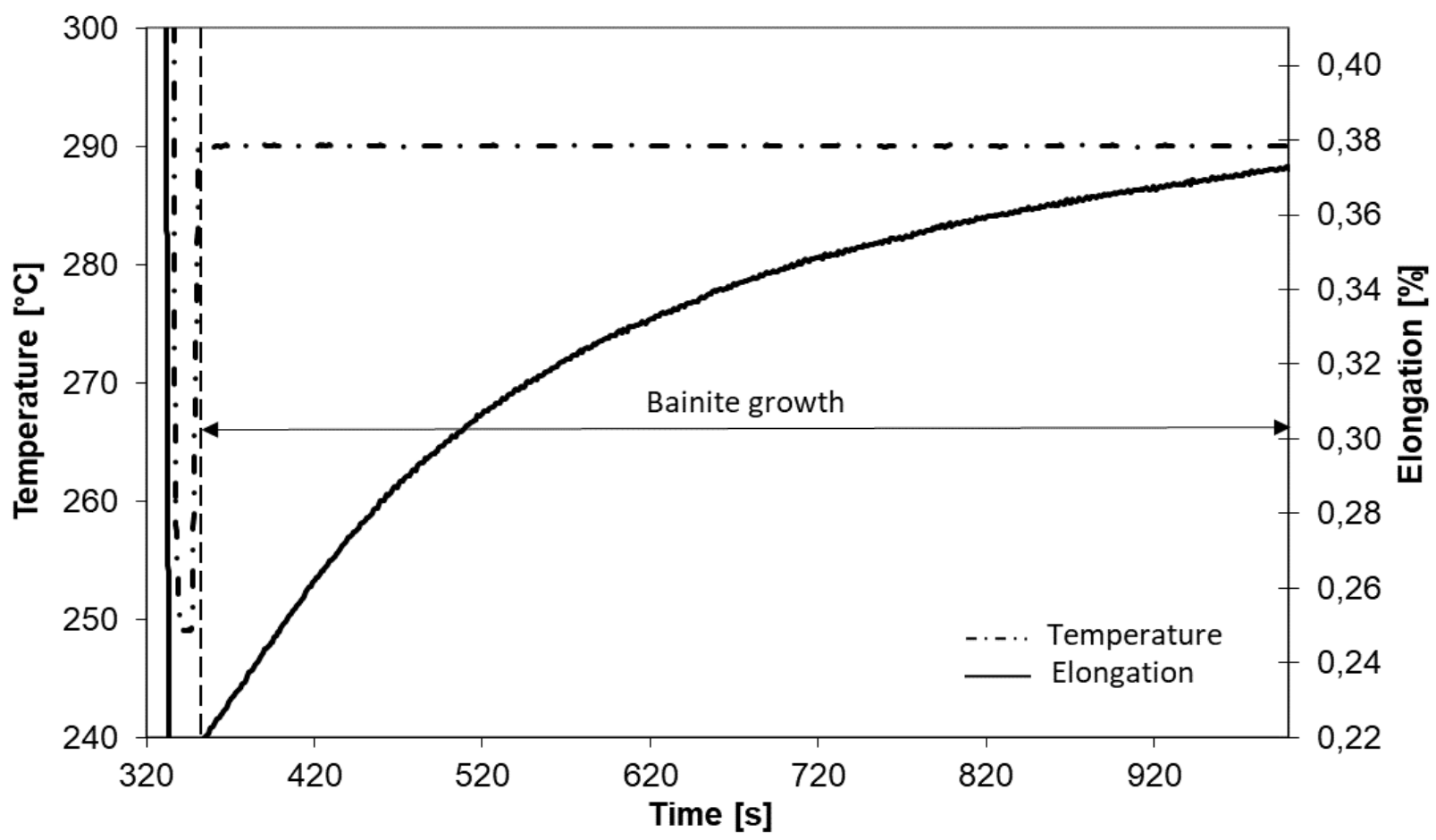

Fig. 8 Details of changes in length during the partitioning state - process route Q-P $250 / 290^{\circ} \mathrm{C}$ 
In process routes Q-P $250 / 290^{\circ} \mathrm{C}, \quad \mathrm{Q}-\mathrm{P}$ $230 / 290^{\circ} \mathrm{C}$ and $\mathrm{Q}-\mathrm{P} 250 / 250^{\circ} \mathrm{C}$, austenite-bainite transformation occurred almost immediately after the partitioning temperature had been reached (Fig. 8 through 10). In process route Q-P $230 / 250^{\circ} \mathrm{C}$, the transformation was preceded by a delay of approximately 50 seconds.

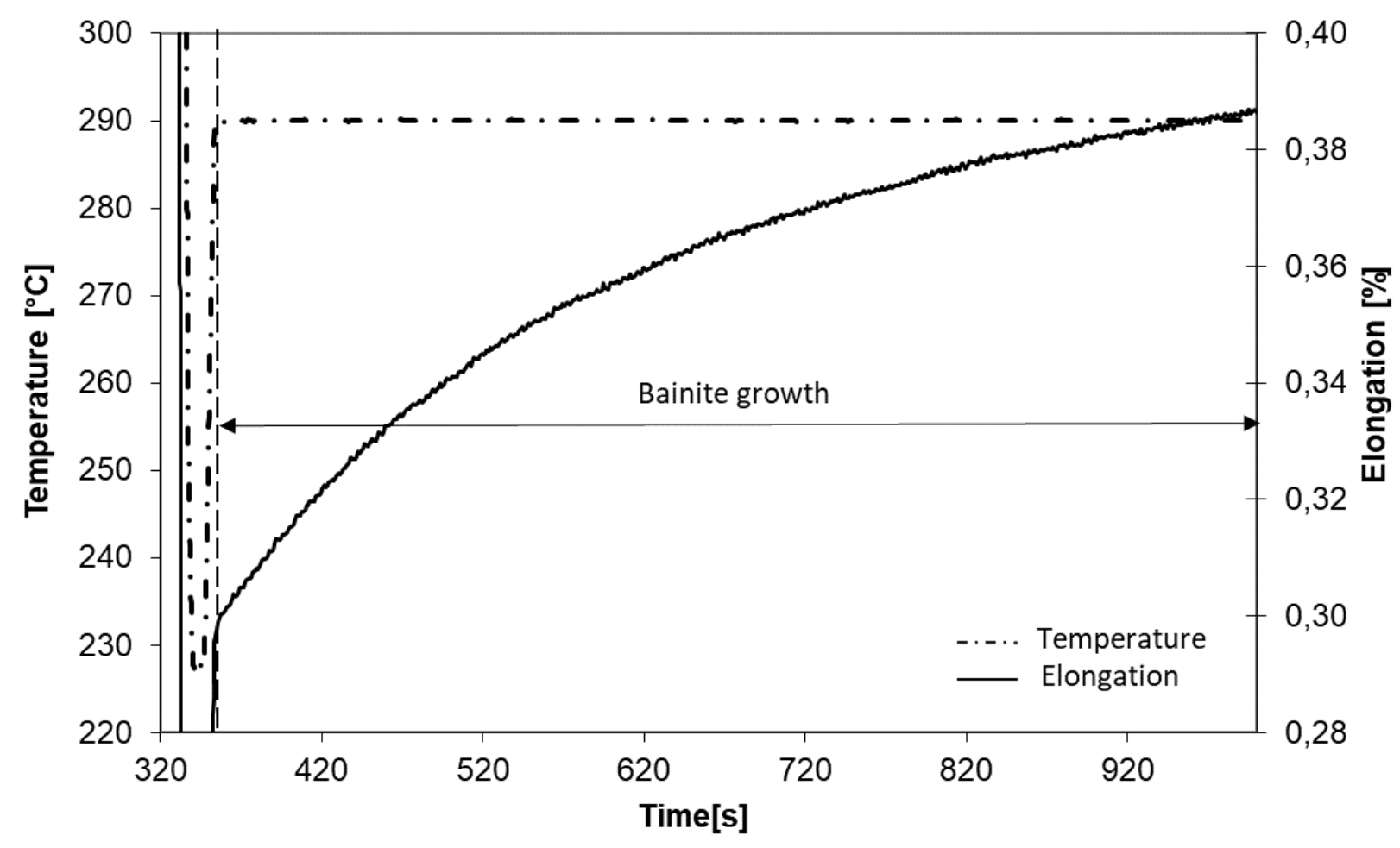

Fig. 9 Details of changes in length during the partitioning state - process route Q-P $230 / 290^{\circ} \mathrm{C}$

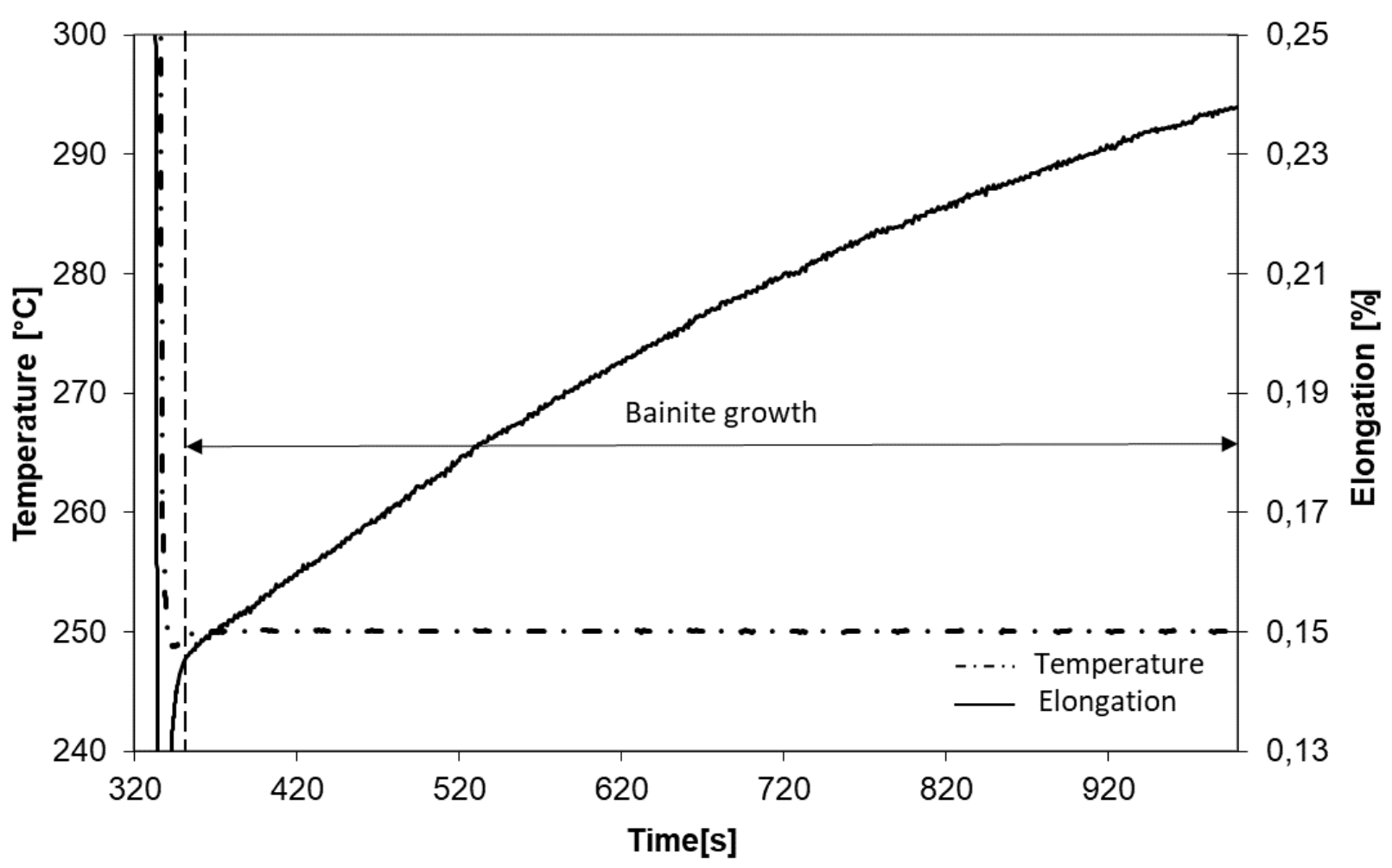

Fig. 10 Details of changes in length during the partitioning state - process route $Q-P 250 / 250^{\circ} \mathrm{C}$ 
Higher quenching and partitioning temperatures (in process routes Q-P $250 / 290^{\circ} \mathrm{C}$ and Q-P $250 / 250^{\circ} \mathrm{C}$ ) led to a markedly extensive bainitic transformation when compared process routes Q-P $230 / 290^{\circ} \mathrm{C}$ and Q-P $230 / 250^{\circ} \mathrm{C}$.

An important question is the key factor which causes bainite to form in untransformed austenite. The presumed cause, operating also at temperatures below the $\mathrm{M}_{\mathrm{s}}$, is the combination of austenite refinement by the presence of martensite particles and plastic deformation at the martensite-untransformed austenite interface.

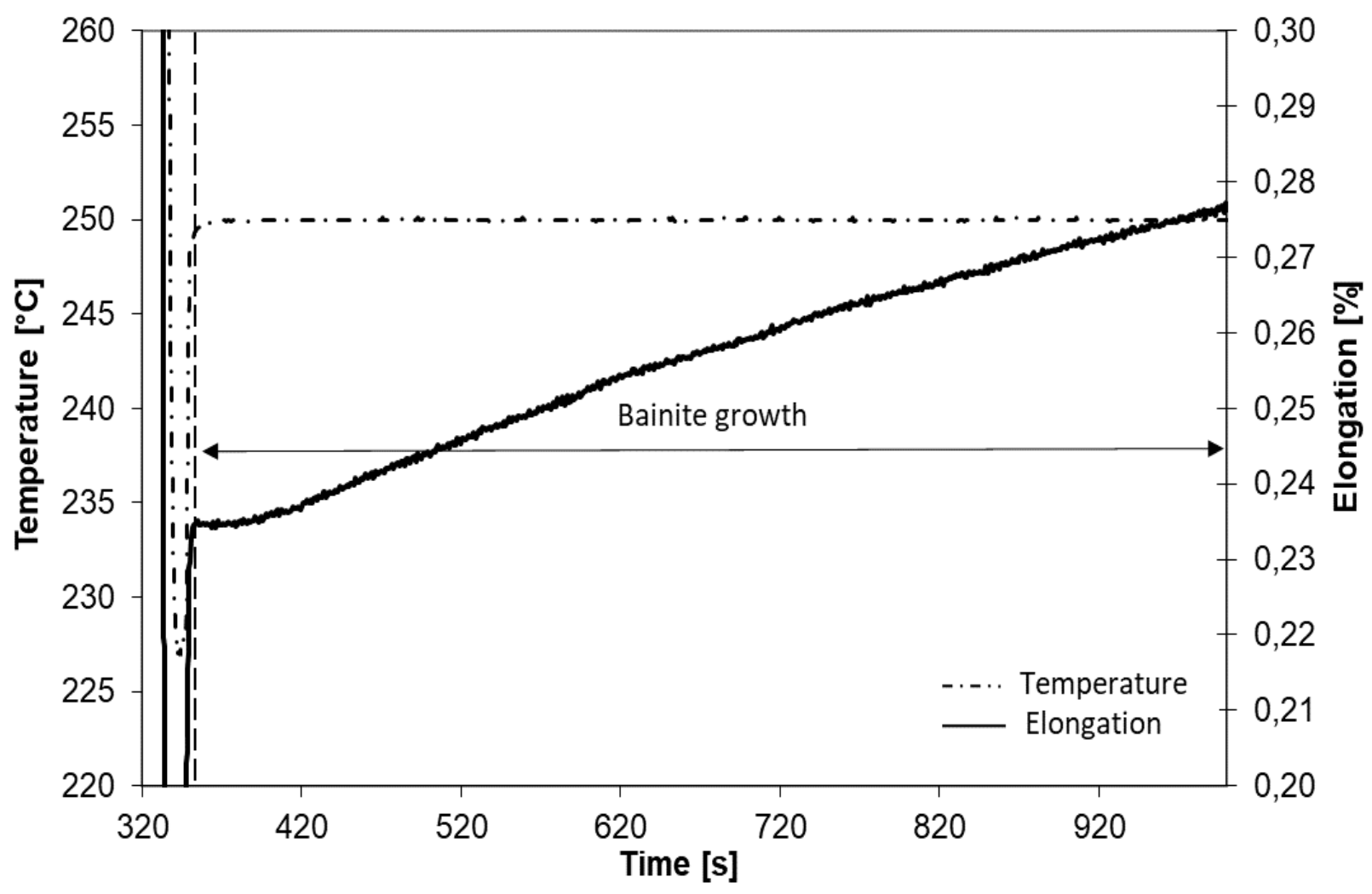

Fig. 11 Details of changes in length during the partitioning state - process route Q-P $230 / 250^{\circ} \mathrm{C}$

\section{Conclusion}

The progress of austenite decomposition in the course of Q-P processing of medium-carbon steel with $0.43 \% \mathrm{C}, 0.55 \% \mathrm{Mn}, 2 \% \mathrm{Si}$ and $1.33 \% \mathrm{Cr}$ was explored. In a quenching dilatometer, specimens were subjected to process routes which enabled the progress of transformation to be monitored and correlated with the quenching and partitioning temperatures.

In all the Q-P process routes, bainitic transformation was induced during partitioning. Its progress was dependent on the Q-P process conditions. The higher the quenching and partitioning temperatures were, the more noticeable the signs of transformation on the dilatometer curve were - indicating higher content of bainite in the microstructure. In turn, lower quenching and partitioning temperatures led to a less pronounced signs of bainitic transformation on the dilatometer curve, which shows that there was less bainite in the microstructure.

Using dilatometer measurement, it was found that bainitic transformation initiated almost immediately after the partitioning temperature had been reached.
The only exception was the Q-P $230 / 250^{\circ} \mathrm{C}$ process route, in which there was about 50 second delay between these occurrences.

Martensite which formed by interrupted quenching had a favourable effect on the decomposition of the remaining austenite to bainite. One can therefore assume that interrupted quenching accelerated the subsequent bainitic transformation. The likely cause is the refinement of the austenite grain due to newly-formed martensite particles and microplastic deformation.

It appears that the decomposition of untransformed austenite to bainite during Q-P processing is the major factor which governs partitioning of carbon and enrichment of retained austenite in Q-P-processed steels.

\section{Acknowledgement}

The present contribution has been prepared with the support of the student grant competition of University of West Bohemia in Pilsen, SGS 2019019. 


\section{References}

[1] MAŠEK, B., OPATOVÁ, K., VOREL, I. (2016). Q-P Process in Manufacture of Hollow Products. In Advanced Materials and Structural Engineering. London: CRC Press, 2016. pp. 467471. ISBN: 978-1-138-02786-2

[2] MAŠEK, B., VOREL, I., JIRKOVÁ, H., KŮRKA, P. (2014). Combination of Internal High Pressure Forming and Q-P Process for Production of Hollow Products from AHS Steel. In COMAT 2014. Ostrava: TANGER Ltd., 2014. pp. 1-7. ISBN: 978-80-87294-45-1

[3] VOREL, I., JENÍČEK, Š., KÁŇA, J., IBRAHIM, K., KOTĚŠOVEC, V., MAŠEK, B. (2017). Effect of silicon content on microstructure of low-alloy Q\&P-Processed steels. In IOP Conference Series-Materials Science and Engineering. Bristol: IOP PUBLISHING LTD, 2017. pp. 1-6. ISBN: not listed, ISSN: $1757-8981$

[4] SUN, J., AND H. YU. (2013). Microstructure Development and Mechanical Properties of Quenching and Partitioning (Q\&P) Steels and an Incorporation of Hot-Dipping Galvanization During Q\&P Process. Material Science and Engineering, 2013, A 586 (1): 100-107.

[5] SETO, K., H. MATSUDA. Application of Nanoengineering to Research and Development and Production of High Strength Sheets. Material Science and Technology 29 (10): 1158-65, 2013

[6] KAWATA, H., K. HAYASHI, N. SUGIURA, N. YOSHINAGA, AND M. TAKAHASHI. Effect of Martensite in Initial Structure on Bainite Transformation. Materials Science Forum 638-642, 2010

[7] SUN, J., H. YU, S. WANG, AND Y. FAN. (2013). Study of Microstructure Evolution, Microstructure- Mechanical Properties Correlation and Collaborative Deformation-Transformation Behavior of Quenching and Partitioning (Q\&P) Steel,2013, Material Science and Engineering A 585:132-38.

[8] GUANGHUA, Y., LIZHAN, H., CHUANWEI, LI., XIAOMENG, L.,
JIANFENG, G. (2017). Characteristic of retained austenite decomposition during tempering and its effect on impact toughness in SA508 Gr.3 steel, 2017, Journal of Nuclear Materials 483, $167-175$

[9] HIDALGOA, J., FINDLEYB, K.O., SANTOFIMIAA, M.J. (2017). Thermal and mechanical stability of retained austenite surrounded by martensite with different degrees of tempering, 2017, Materials Science \& Engineering A 690, 337-347

[10] J. HIDALGO, K.O.FINDLEY, M.J.SANTOFIMIAA (2017). Thermal and mechanical stability of retained austenite surrounded by martensite with different degrees of tempering, Materials Science and Engineering: A,Volume 690, 2017, Pages 337-347

[11] PEKOVIĆ, M., VOREL, I., KÁŇA, J., OPATOVÁ, K. (2017). Evolution of microstructure and mechanical properties in steels during isothermal holding in the region of bainitic transformation temperature in dependence on silicon content. Manufacturing Technology, 2017, Vol. 17, No. 4/2017, pp. 549-555. ISSN: 1213-2489

[12] PEKOVIĆ, M., JENÍČEK, Š., VOREL, I., KÁÑA, J., OPATOVÁ, K. (2017). Vliv křemíku na vývoj mikrostruktury ocelí při izotermické prodlevě v oblasti teplot bainitické transformace. Strojirenská technologie, 2017, Vol. 22, No. 1, pp. 53-57. ISSN: 1211-4162

[13] KOTĚŠOVEC, V., VOREL, I., JENÍČEK, Š., KÁŇA, J., IBRAHIM, K. (2017). Impact of quenching temperature and isothermal holding time during austempering on bainite content in high-silicon steel. In IOP Conference Series-Materials Science and Engineering. Bristol: IOP PUBLISHING LTD, 2017. pp. 1-5. ISBN: not given, ISSN: 1757-8981

[14] BUBLÍKOVÁ, D., JIRKOVÁ, H., BEHÚlOVÁ, M., KRAJČOVIČ, J. (2019). Determination of transformation temperatures in advanced high-strength steels and their use in designing of Q\&P process routes. Manufacturing Technology, 2019, Vol. 19, No. 1/2019, pp. 18-22. ISSN 1213-2489 